\title{
Natural disasters and 150th commemoration of Canada as a country
}

\author{
Nirupama Agrawal ${ }^{1} \cdot$ Robin Cox $^{2}$
}

Published online: 19 August 2019

(c) Springer Nature B.V. 2019

As the second largest country in the world, and as a country characterized by enormous geographical and climatic diversity, Canada faces enormous challenges related to disaster and climate risks. In this special edition, some of Canada's leading disaster researchers share insights and trends in disaster risks and resilience through the examination of historical and recent natural-hazard- and weather-related disasters in Canada. In a recent report by Statistics Canada, over 12.4 million Canadians reported experiencing a major emergency or disaster in their lifetime, with three quarters of those indicating that their experience was "significant enough to have severely disrupted their regular daily routine" (Statistics Canada, 2016). Since Confederation in 1867 (Fig. 1), Canada has gone through numerous territorial changes and expansions to become a union of ten provinces and three territories and 22 self-governing First Nations and Inuit. As part of these changes, Canada has recently begun a process of reconciliation with Indigenous peoples in Canada. The Truth and Reconciliation Commission (TRC) of Canada was founded in June 2008 in 2015 with the purpose of documenting the history and lasting damaging impacts of the Canadian Indian residential school system on indigenous peoples. Since the conclusion of the TRC in 2015, a 'Calls to Action' report has identified areas to address, such as child welfare, education, health, justice, to name a few.

These calls to action, and the reflection and actions they are inspiring are particularly relevant to this Special Issue. Disaster research has clearly demonstrated the primary role that social, economic and political justice has on disaster and climate-related vulnerability and resilience for all people. This Special Issue (SI), therefore, is dedicated to the next 150 years of Canada with the hopes that the equality and wellbeing of all peoples will be protected and that these values will infuse actions by governments and civil society to reduce the personal, social, and economic costs and impacts of the escalating disaster and climate risks we all face in the context of global warming.

Based on the available disaster database compiled by Public Safety Canada, Canada has experienced 865 natural disasters since the beginning of the twentieth century. In light of

Nirupama Agrawal

nirupama@yorku.ca

Robin Cox

robin.cox@royalroads.ca

York University, Toronto, ON, Canada

2 Royal Roads University, Victoria, BC, Canada 


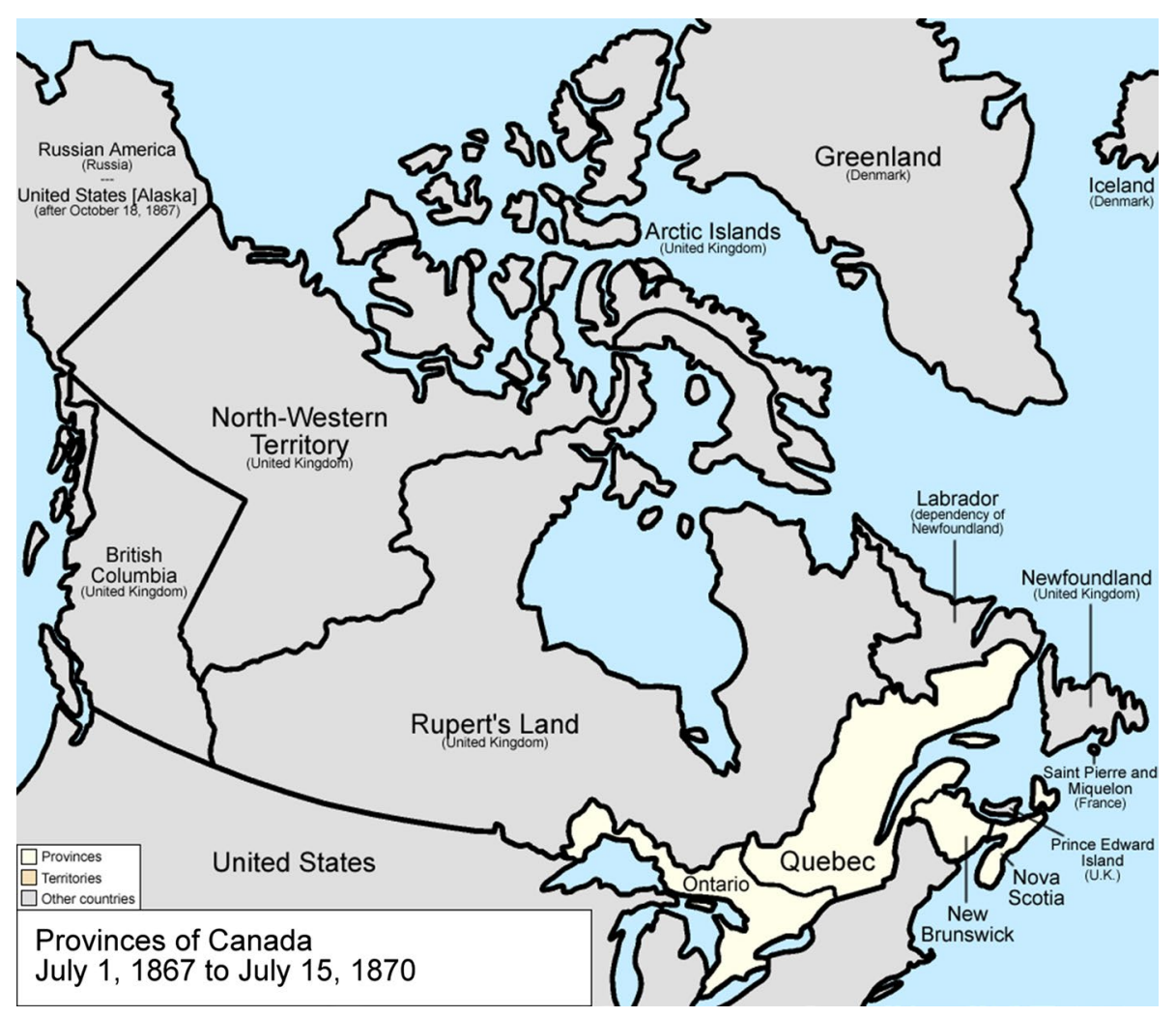

Fig. 1 Canadian territory at confederation (Wikipedia, Golbez, based on copyright claims)

the ongoing climate uncertainties, it is imperative to note that Canada has been experiencing unprecedented floods and wild fires in recent times. This SI takes stock of hazards originated from natural hazards that - in most cases - turn into disasters by directly impacting people, properties, and the environment. It is designed to provide snapshots of some of the key events. Although the intent was to cover the entire period in time and space, selected case studies and modeling scenarios make up the majority of the articles in the SI.

These scenarios and case studies provide a glimpse into the history of natural-hazardrelated disasters over history. They include historically hazardous weather events in the St Lawrence Valley region in Québec_-particularly Quebec City and the City of Montrealcontributed by Slonosky for the period between 1742 and 1869. The author observes that annual frequencies of most events fall broadly within the same ranges over the course of the past centuries. However, a decrease in the number of consecutive dry days and a concomitant increase in precipitation-related hazardous events such as thunder and freezing rain can be seen in the twentieth and early twenty-first centuries compared to the nineteenth century. Agrawal and Jahanandish present an interesting angle on the impacts of climate change on the world's longest outdoor skating rink, the Rideau Canal Skateway. The authors demonstrate that in addition to the local weather parameters, large-scale oceanic oscillations, such as Arctic Oscillation (AO) and North Atlantic Oscillation (NAO), are equally significant in determining the variabilities in skating seasons. Godsoe et al. 
investigate Canada's disaster baselines and projections under the Sendai framework for disaster risk reduction (DRR). Their research employs the UN methodology to create baselines and targets for Canada and extends the methodology further by developing a statistical modeling software application to project future trends to the year 2030. Though the model projections suggest Canada may have challenges ahead, with a recently announced infrastructure investment plan, there is an opportunity for Canada to better manage disaster risks by building better and smarter. Cox et al. attempt to shift the conventional perception of young children and youth as a population at high risk of experiencing negative impacts during disasters, to one that recognizes them as having potential as change agents in their communities. The authors argue that as the first digitally native generation, youth today are equipped with unprecedented technological savvy, an entrepreneurial orientation, and confidence in their ability to make a difference in DRR in Canada. The 2003 outbreak of the severe acute respiratory syndrome (SARS) made its mark in the history of disasters as a first of its kind public health emergency. O'Sullivan and Phillips use the outbreak to realize occupational health risks faced by health care workers and first responders in public health emergency response. They reflect on how the framing of vulnerable or high-risk populations has evolved since SARS and discuss ideas around the creation of institutional space for engagement of high-risk populations in pandemic planning processes, including participatory governance.

Floods are the number one hazards in terms of economic and infrastructural damage in Canada. Using the case of the Province of Manitoba, Haque et al. examine how various disaster management institutions and policies have changed over the years, drawing insights from the existing literature, including the Birkland's policy change and learning framework, Peter May's categorization of policy learning, and other social learning literature. The findings of the study reveal that significant policy changes were made in response to sever historical events such as the droughts of the 1930s; the floods of 1950, 1966, 1997, and 2011; and the wildfires of 1989. Doberstein et al. propose an interesting framework, "protect/accommodate/retreat/avoid" (PARA) that categorizes flood disaster risk reduction approaches best for building climate change resilient communities across Canada. The paper uses four cases of floods in the country with each case chosen to represent one of the four 'PARA' risk reduction options. For example, zoning changes and land expropriation following Toronto's 1954 Hurricane Hazel flood disaster are used to showcase the "retreat" approach, and modern floodplain development planning approaches in Calgary, Alberta, are used to highlight the "avoid" approach. Chang et al. discuss the effects of urban development on future multi-hazard risk using the case of Vancouver, Canada. The paper models current and future risk for the year 2041 in a rapidly growing urban area of the City, from both earthquake and coastal flood hazard perspectives. The findings highlight the importance of considering natural hazard risk in urban development planning, and of recognizing the inherent differences between hazards and impact types in this planning. The devastating 1996 Saguenay flood in the Province of Quebec is explored by Tremblay and Guillaud, with a focus on minimizing similar risk in the future by implementing legislative as well as dam safety measures. Another important 2-part study using the same 1996 Saguenay flood is contributed by AlQasimi and Tew-Fik with two major rivers as points of focus, namely the Aux Sables and Ha! Ha! They used the modeling tool UMHYSER-1D to model morphological changes along the Ha! Ha! River. Additionally, they investigated the suspended sediment impact for the Aux Sables River enabling the maximum permissible sediment discharge to be released into the river while avoiding any risk of pollution for the population of the City of Jonquiere. The authors have successfully demonstrated the important role of numerical modeling in solving complex engineering problems. 
The year 2016 was marked by severe wildfires in and around the City of Fort McMurray in the Province of Alberta. The fires resulted in the largest evacuation in the history of the province. Exploring the wildfire through the lens of the four pillars of emergency management: response, recovery, mitigation, and preparedness, Mamuji and Rozdilsky note that the country can better ready itself for a future where fires could be one of the primary natural disasters reshaping Canadian landscapes. In another study, Slick explores a phenomenological study of YouTube videos of the Fort McMurray wildfires. The City was captured by citizens on videos and shared on YouTube that the author used as a data source for exploring peoples' lived experiences with the wildfire. Christianson and McGee recount the experiences of the mandatory wildfire evacuation being put in place during the Whitefish Lake First Nation 459 in the Province of Alberta in 2011 and examine the impact and effectiveness of the measure. In their analysis, jurisdiction stands out as an overarching factor that affected the entire evacuation process. Based on the findings, author has offered recommendations for emergency managers on improving wildfire evacuation experiences for Indigenous peoples in Canada.

The West Coast of Canada is a known subduction zone with significant risk from tsunamigenic earthquakes. Using the Town of Tofino, a small community located on the west coast of Vancouver Island in British Columbia, Cheff et al. demonstrate that three vertical evacuation buildings can reduce the risk of losing population by $99 \%$ in the area. This is the first Canadian study which uses anisotropic evacuation modeling to evaluate community vulnerability to tsunami inundation. Shahbaboli et al., in their 2-part study, explore tsunami bore effects on structures with focus on Drag Coefficients and effects of bed condition on loading onto circular structures. They calculated hydrodynamic forces and associated drag coefficients and compared them with data in the existing literature and current design codes. Furthermore, a broad investigation on bore propagation characteristics is performed and presented. A comparison is made between the stream-wise forces exerted on the structural column as well as the bore velocity and results analyzed for smooth, rough, dry and wet beds with varying depths. Further on Vancouver Island, Canada, Takabatake uses numerical simulations to estimate the spatiotemporal characteristics of tsunami inundation for municipalities on the island. The numerical results show that the maximum tsunami inundation depth and spatial extent of inundation are sensitive to the earthquake magnitude, but the tsunami arrival time is not. The study also estimates potential damage with previously proposed fragility curves for wood, reinforced concrete and steel frame buildings. Lastly, risk perception and people's behavior are nuanced by Yong and Lemyre in their comprehensive work on risk communication strategies using a socio-ecological approaches. The work is particularly important in an increasingly diverse Canada where individuals may perceive and understand natural disaster risks as they fit in their social and life contexts. Using a cultural lens to contrast immigrants to Canadian-born individuals, the paper brings a better understanding of how to engage Canadians in disaster preparedness and risk management.

This issue and the studies it features provide an important snapshot not only of the history of natural-hazard-related disasters in Canada, but also insights into the trends we can anticipate moving forward. While it is impossible to predict the disaster-related impacts of climate change with certainty, it is already clear that climate change is increasing the frequency and intensity of disaster risks and in this context, disaster risk reduction has become a critical issue both in Canada and globally. According to the latest Climate Change Canada 2019 report, beyond the next few decades, the main uncertainty about the scale of future climate change is rooted in uncertainty related to the success of our global efforts to reduce our reliance on carbon-based energy and the greenhouse gas emissions 
from these systems wide dependencies. Given this uncertainty, it is important to develop policy and practices informed by climate mitigation and adaptation to reduce disaster risk in the coming decades.

Guest Editors

Nirupama Agrawal

Robin Cox

Publisher's Note Springer Nature remains neutral with regard to jurisdictional claims in published maps and institutional affiliations. 